El graffiti

en la imagen urbana

de la ciudad

de Masaya.

Arq. Gema Margarita Morales Cuadra 


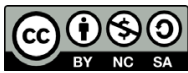

\section{El graffiti en la imagen urbana de la ciudad de Masaya}

Arq. Gema Margarita Morales Cuadra* UNAN-Managua, Nicaragua https://orcid.org/0000-0001-7409-9750 garzamorena78@hotmail.com

Recibido: 07/09/2018 Aceptado: $28 / 10 / 2018$

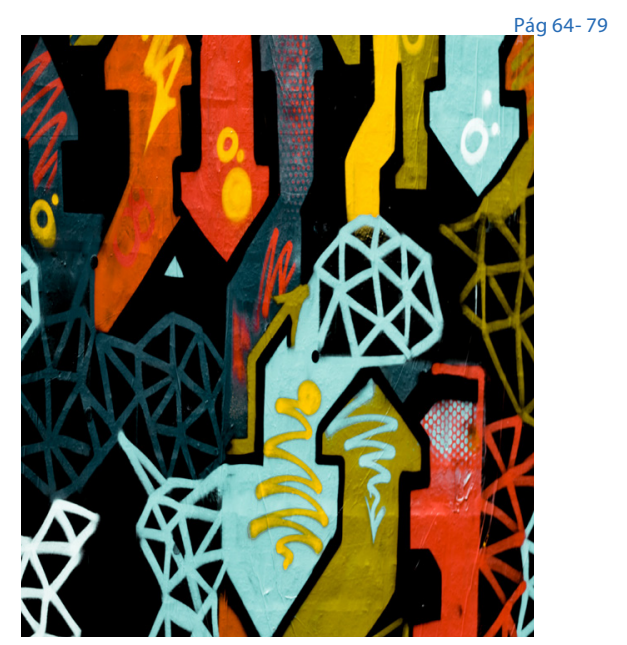

\section{PALABRAS CLAVE}

Masaya, Paisaje Urbano, Imagen Urbana, Arte Urbano, Grafiti.

\begin{abstract}
El trabajo que se presenta a continuación consistió en la identificación y clasificación de los grafitis en el casco urbano de la ciudad de Masaya. El proceso metodológico parte de la definición de los aspectos conceptuales referentes al paisaje urbano, la imagen urbana, el arte urbano y en específico el grafiti. Esto permitió un mejor manejo de la temática en el proceso del levantamiento fotográfico y mapeo que se realizó de los elementos de la imagen urbana de la ciudad más intervenidos por el grafiti. Posteriormente, se clasificaron de acuerdo a los estándares internacionales. Esto logró evidenciar como es el comportamiento de este arte callejero dentro de la imagen del casco urbano de Masaya.
\end{abstract}

\section{ABSTRACT}

The work presented below consisted in the identification and classification of graffiti in the urban area in the city of Masaya. The methodological process starts from the definition of the conceptual aspects related to the urban landscape, the urban image, the urban art and specifically the graffiti. This allowed a better management of the theme in the process of photographic survey and mapping that was made of the elements of the urban image of the city most intervened by graffiti. Subsequently, the graffiti were classified according to international standards. This managed to show how is the behavior of this street art within the image of the urban area of Masaya

\section{KEYWORDS}

Masaya, Urban Landscape, Urban Image, Urban Art, Graffiti. 


\section{Introducción}

Cuando se recorren las diferentes calles de la ciudad de Masaya, se pueden apreciar muchas obras artísticas reconocidas por los pobladores como murales, que sin duda embellecen el contexto urbano. Esto ha surgido por iniciativa de los nuevos talentos artísticos que pretenden mostrar su cultura e identidad. Igualmente, en Masaya hay expresiones de grafitis que mantienen la técnica del spray y el esténcil, así como su carácter subversivo y que muchas veces son confundidas como obras del muralismo.

Debemos comprender que la ciudad de Masaya posee una gran riqueza cultural que la convierte en un contexto urbano donde coexiste una pluralidad de tendencias artísticas y la mistura del pasado con la contemporaneidad y podríamos decir que el grafiti que se evidencia, es producto de esto. Pero, es preciso conocer el comportamiento de esta disciplina dentro de los elementos del paisaje urbano de la ciudad para definir cuáles son los puntos más frecuentes de su intervención.

Es por esta razón, que se quiso hacer una reflexión sobre el intercambio de estos espacios urbanos y las distintas expresiones de grafiti, el cual va ganando y marcando territorialidad, haciendo de este trabajo artístico, toda una profesión de tiempo completo.

\section{Material y métodos}

La presente investigación se basó en la identificación de los elementos del paisaje urbano de la ciudad de Masaya y el levantamiento de los grafitis existentes en el mismo. El estudio surge desde el enfoque filosófico de la investigación cualitativa. El método empleado es la etnografía, con la técnica de observación.

El campo de estudio está determinado por todo lo relacionado el grafiti que se encuentra en el paisaje urbano, mismo que construye la imagen urbana y las expresiones de arte. El universo en el que se basa la investigación está conformado por los grafitis localizados en los centros urbanos de las ciudades de Nicaragua. La población responde a las expresiones artísticas permanentes y el espacio urbano de la ciudad de Masaya. La muestra que se extrajo para la investigación estuvo determinada por los elementos del paisaje urbano y los grafitis del casco urbano de la ciudad de Masaya. Los criterios de selección responden a la identificación de los componentes más determinantes de la imagen urbana de la ciudad, y la ubicación de todos los grafitis existentes.

Los métodos, técnicas e instrumentos usados fueron, un levantamiento fotográfico y planimetría de la identificación de los elementos del paisaje urbano y los grafitis del casco urbano de Masaya. Para definir los componentes básicos del paisaje urbano se aplicó la tabla de factores determinantes expuesta por el Arq. Roberto Rodríguez Valdés (Ver Tabla No. 1) y la clasificación de los grafitis fue en función de los criterios universales definidos por los mismos grafiteros en cuanto a la forma y contenido de sus propuestas artísticas. 
Tabla No.1 Componentes del paisaje urbano

\begin{tabular}{|l|l|l|l|}
\hline $\begin{array}{l}\text { Factores } \\
\text { determinantes }\end{array}$ & $\begin{array}{l}\text { Estrategia del paisaje } \\
\text { urbano }\end{array}$ & \multicolumn{2}{|c|}{ Componentes básicos } \\
\hline $\begin{array}{l}\text { Determinantes } \\
\text { físico-naturales }\end{array}$ & \multicolumn{1}{|c|}{$\begin{array}{c}\text { Componentes } \\
\text { puntuales }\end{array}$} & \multicolumn{2}{|c|}{ Edificios relevantes y carácter patrimonial } \\
\hline $\begin{array}{l}\text { Determinantes } \\
\text { socio-culturales }\end{array}$ & $\begin{array}{l}\text { Componentes } \\
\text { longitudinales }\end{array}$ & Calles & Avenidas \\
\cline { 3 - 4 } & Calles \\
\hline $\begin{array}{l}\text { Determinantes } \\
\text { urbanos }\end{array}$ & $\begin{array}{l}\text { Componentes } \\
\text { extendidos }\end{array}$ & Plazas & Callejones \\
\hline
\end{tabular}

Fuente: Rodríguez Valdés, Roberto (2008). El paisaje urbano en el centro histórico de Santiago de Cuba: método gráfico-teórico para su caracterización morfotipológica. Universidad de Oriente. Santiago de Cuba. p. 50

\section{Antecedentes: un poco de historia de los grafitis}

El graffiti de Nueva York en los años setenta, tuvo su máxima expresión en las paredes con mensajes plasmados básicamente en dos formas: a manera de pintas y de esténciles. Las pintas consistían en palabras escritas con spray, a menudo como protesta sin ningún interés estético o artístico, puesto que eran creadas en espacios públicos de prisa; ya que, en esa época, el ser descubierto implicaba consecuencias graves, incluso hasta la propia desaparición del escritor.

En Nicaragua, luego del triunfo de la Revolución Popular Sandinista en 1979, el Estado promueve la creación de "graffitis populares", que técnicamente hablando, eran murales con carácter patriótico, cuyo contenido era el triunfo y los héroes de la guerra; pero lo novedoso fue que se introdujeron técnicas artísticas, como la luz y la sombra, así como la profundidad y superposición de las formas. Simultáneamente, surge la primera generación de grafiteros muy marcada por la escuela de la "La Gran Manzana de New York" y otras ciudades de E.E.U.U. Su principal estrategia consistía en rastrear las imágenes que se reproducían en esos contextos de ciudad.

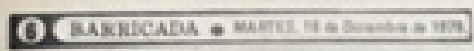

A problemas sociales soluciones comunales

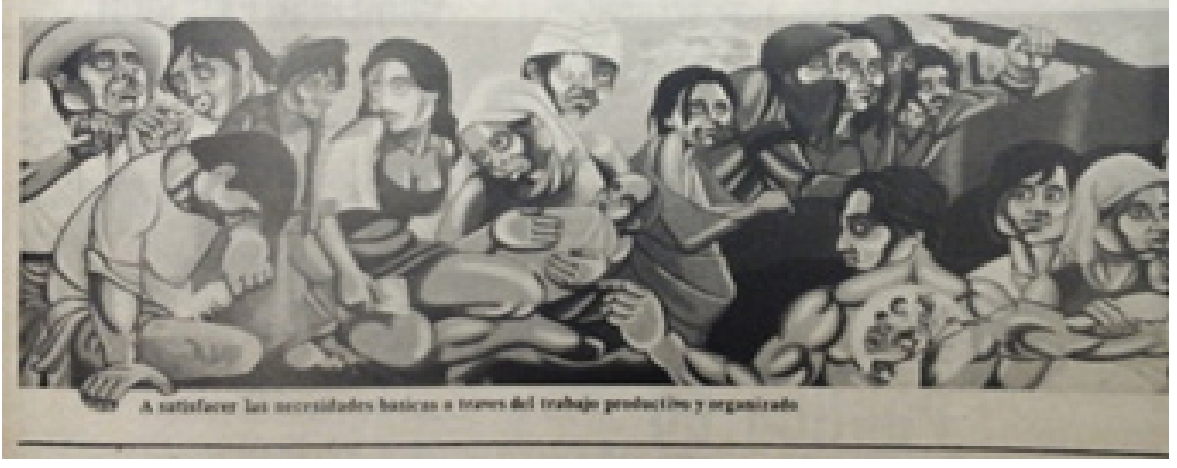

Figura No.1 Ejemplo de grafitis populares de 1979

Fuente: Hemeroteca. Archivo Municipal de Managua. (1979). Diario Barricada.18 de diciembre, pág. \# 6. 
Como se indica, los inicios de nuestro graffiti estuvieron influenciados por la política nicaragüense de los años setenta, pero, esto hoy en día no le ha quitado su carácter de expresión social, puesto que influye desde el espacio físico e interactúa con los transeúntes; sin embargo, no todos lo consideran como una categoría del arte urbano, quizá por su contenido o visión de la realidad, puesto que genera debates sobre sus mensajes y su lucha contra el bombardeo mediático; pero, a pesar de las reacciones y de ser determinado más como una expresión de cultura ajena que de la propia, se encuentra en proceso de expansión territorial dentro de los centros urbanos.

Es por esta razón, que se considera una tarea permanente el hecho de vigilar el trabajo de estos artistas callejeros, que forman parte de la imagen urbana de nuestras ciudades. En función de esto se han registrado algunas investigaciones sobre esta temática en el contexto nacional:

David Kunzle publicó un libro sobre murales de la Nicaragua Revolucionaria entre 1979-1992, cuya primera publicación fue en 1995 en inglés en los Estados Unidos, y una segunda en español en el año 2017 en Nicaragua. Este registro puede ser el único archivo existente de estas obras, ya que registra aproximadamente el ochenta por ciento de los que se han elaborado. Muchos van acompañados con un amplio comentario sobre su estilo y las escuelas, que van desde la estética primitivista a la altamente sofisticada. Él relata la destrucción de este importante patrimonio cultural de Nicaragua, debido a condiciones políticas coyunturales, acción que atenta contra la preservación de la memoria colectiva. También se refiere a otros medios de arte público en Nicaragua, como los carteles y el graffiti. El principal objetivo del libro de Kunzle era registrar y documentar la existencia de estas obras de arte, así como evidenciar el contexto histórico que las inspiró y generó.

"El graffiti y los derechos de autor", es un artículo publicado en el año 2014, por Johann Bonilla, con el objetivo de traer a la palestra la problemática que surge en torno al graffiti como obra y al potencial reconocimiento de derechos sobre el mismo. Plantea cuestionantes referentes a sí el graffiti es una obra apta para ser protegida por los derechos de autor y si fuese así, qué modalidad de protección merecería o bien qué pasa cuando el graffiti se plasma en propiedad privada o en espacios públicos susceptibles de reutilización constante.

Katherine Melissa Vanegas Orozco y Juan Carlos Márquez Cerda (2015), para obtener el título de comunicador social en la Facultad de Humanidades y Comunicación de la Universidad Centroamericana, UCA, elaboran un estudio sobre el grafiti como forma de comunicación alternativa en las zonas urbanas de la ciudad de Managua, el trabajo consistió relatar a través de la fotografía, los contenidos de las representaciones artísticas, estéticas y sociales que emplean los grafiteros en las zonas urbanas de Managua como una forma de expresión.

"El grafiti en la capital" es un artículo publicado en el año 2015, que registra los grafitis expuestos en los muros perimetrales de la Universidad Centroamericana y entrevista a algunos de sus autores. Esta publicación ilustra una serie de obras creativas con diversas temáticas cuya modalidad es ser sustituidas cada cierto período de tiempo generando una actualización consecutiva.

"El graffiti supera la clandestinidad" es un artículo publicado por el Nuevo Diario en el año 2016, que documenta el trabajo artístico que realizaron los 18 grafiteros nicaragüenses en el paso a desnivel Rubenia bautizada como Barricada.

Estos datos nos dan referencia del nivel de interés por investigar esta temática por parte de las instituciones estatales, instituciones académicas y comunicadoras para posteriormente difundir el quehacer de estos artistas urbanos. No obstante, es preciso fomentar el registro de estos trabajos que por su carácter efímero se pueden perder de un momento a otro dentro de la memoria colectiva de nuestras ciudades. 


\section{Paisaje urbano}

Es el resultado de la configuración espacio temporal de un sitio, expresada a través de la conjunción de un grupo de elementos físicos, naturales y humanos, donde se manifiesta un notable predominio de las estructuras construidas y usadas por el hombre -edificios, espacios públicos, redes técnicas, mobiliario urbano, entre otros - sobre los restantes elementos. ${ }^{1}$

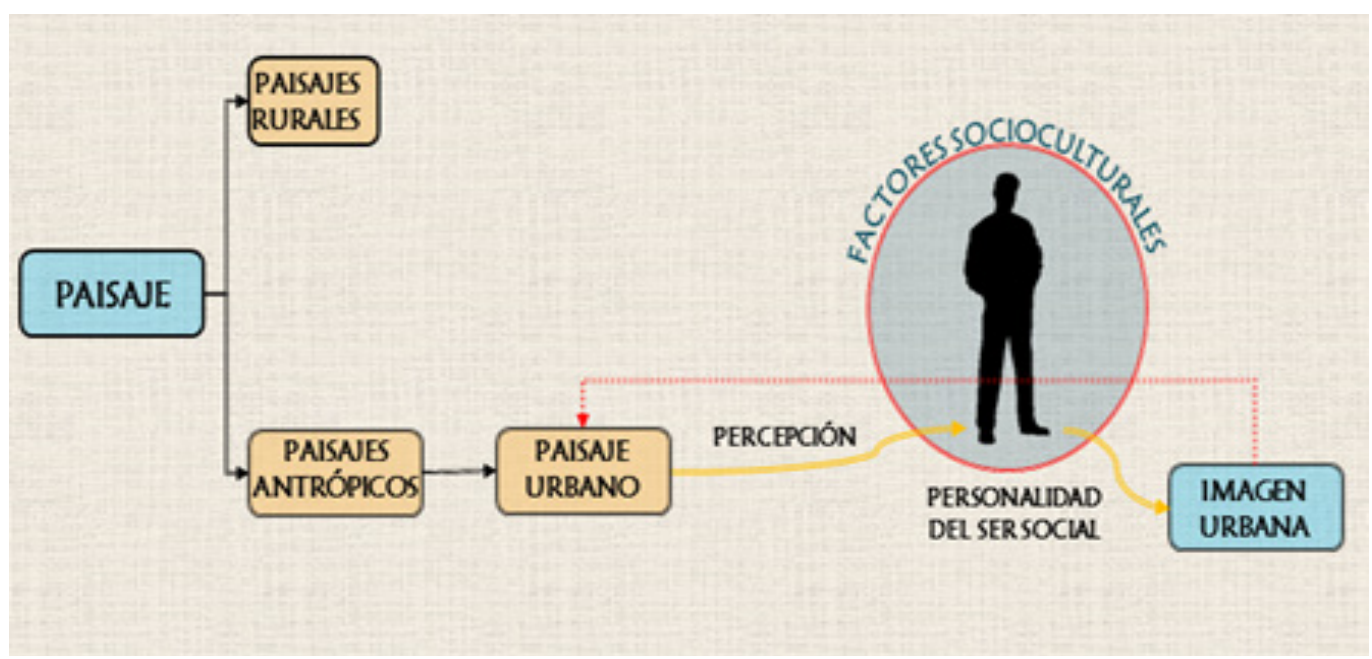

Figura No.2 Esquema general del proceso metódico planteado para el análisis morfotipológico del paisaje urbano.

Fuente: Rodríguez Valdés, Roberto (2008). El paisaje urbano en el centro histórico de Santiago de Cuba: método gráfico-teórico para su caracterización morfotipológica. Universidad de Oriente. Santiago de Cuba. p. 20

\section{Imagen urbana}

Se le puede denominar a los diferentes elementos naturales y construidos por el hombre que se conjugan para conformar el marco visual de los habitantes de la ciudad, relacionando de manera directa sus usos y costumbres. ${ }^{2}$ Se puede reducir el concepto de imagen urbana a la imagen mental, es decir, un producto de la percepción, una prolongación o reverberación de los estímulos periféricos que son procesados por el cerebro a partir de la lectura del entorno citadino. ${ }^{3}$ (Ver figura No. 2)

\section{Arte urbano}

Surge como una forma de expresión reivindicativa de críticas u opiniones sobre la situación social de aquellos grupos sociales que habitan en las distintas zonas urbanas de una ciudad. ${ }^{4}$ Podemos considerar dos características básicas para explicar esta existencia del arte urbano:

- Los criterios y anhelos de los grupos o comunidades integrantes de la sociedad son reflejo de su naturaleza y tratan de expresar con imaginación sus sentimientos, sueños y realidades.

- Se formula para ser disfrutado por una mayoría de la población, y por lo tanto, no se apoya en criterios estéticos obsoletos o temáticas que están lejos de esta mayoría y, sobre todo, busca espacios nuevos para que esta proximidad sea más efectiva.

1. Rodríguez Valdés, Roberto (2008). El paisaje urbano en el centro histórico de Santiago de Cuba: método gráfico-teórico para su caracterización morfotipológica. Universidad de Oriente. Santiago de Cuba. p. 18.

2. https://desarrollourbano.wordpress.com/imagen-urbana

3. Rodríguez Valdés, Roberto (2008). El paisaje urbano en el centro histórico de Santiago de Cuba: método gráfico-teórico para su caracterización morfotipológica. Universidad de Oriente. Santiago de Cuba. p. 20 


\section{Grafiti}

Se llama pintada, grafito o grafiti (las dos últimas del italiano graffiti, graffire, y este a su vez del latín scariphare, 'incidir con el scariphus' - estilete o punzón, con el que los antiguos escribían sobre tablas -) a una modalidad de pintura libre, destacada por su ilegalidad, generalmente realizada en espacios urbanos. Su origen se remonta a las inscripciones que han quedado en paredes desde los tiempos del imperio romano, especialmente las que son de carácter satírico o crítico. Para denominar estas inscripciones de época arqueológica es más frecuente el uso de la palabra «grafito».

\section{Muralismo}

El muralismo es un movimiento artístico iniciado en México, el cual surgió en el año 1922. Artistas e intelectuales mexicanos participaron en la construcción de una nueva identidad nacional. Buscaban consolidar los ideales sociales creados en la revolución, destacando el nacionalismo dentro de su arte, además de cambiar las ideas raciales preexistentes contra los indígenas, ideas que se habían creado durante el periodo colonial.

A pesar de la larga tradición en la historia del arte, el muralismo en la actualidad se manifiesta básicamente en el espacio urbano, donde se representan imágenes artísticas de temáticas distintas. Las paredes de las ciudades son el escenario de esta forma de expresión artística. Pero, en el mundo de los artistas que trabajan sobre las paredes suele haber una discusión sobre la diferencia entre muralismo y grafiti. A continuación, se ilustra la comparación entre los recursos técnicos característicos de cada una de estas expresiones.

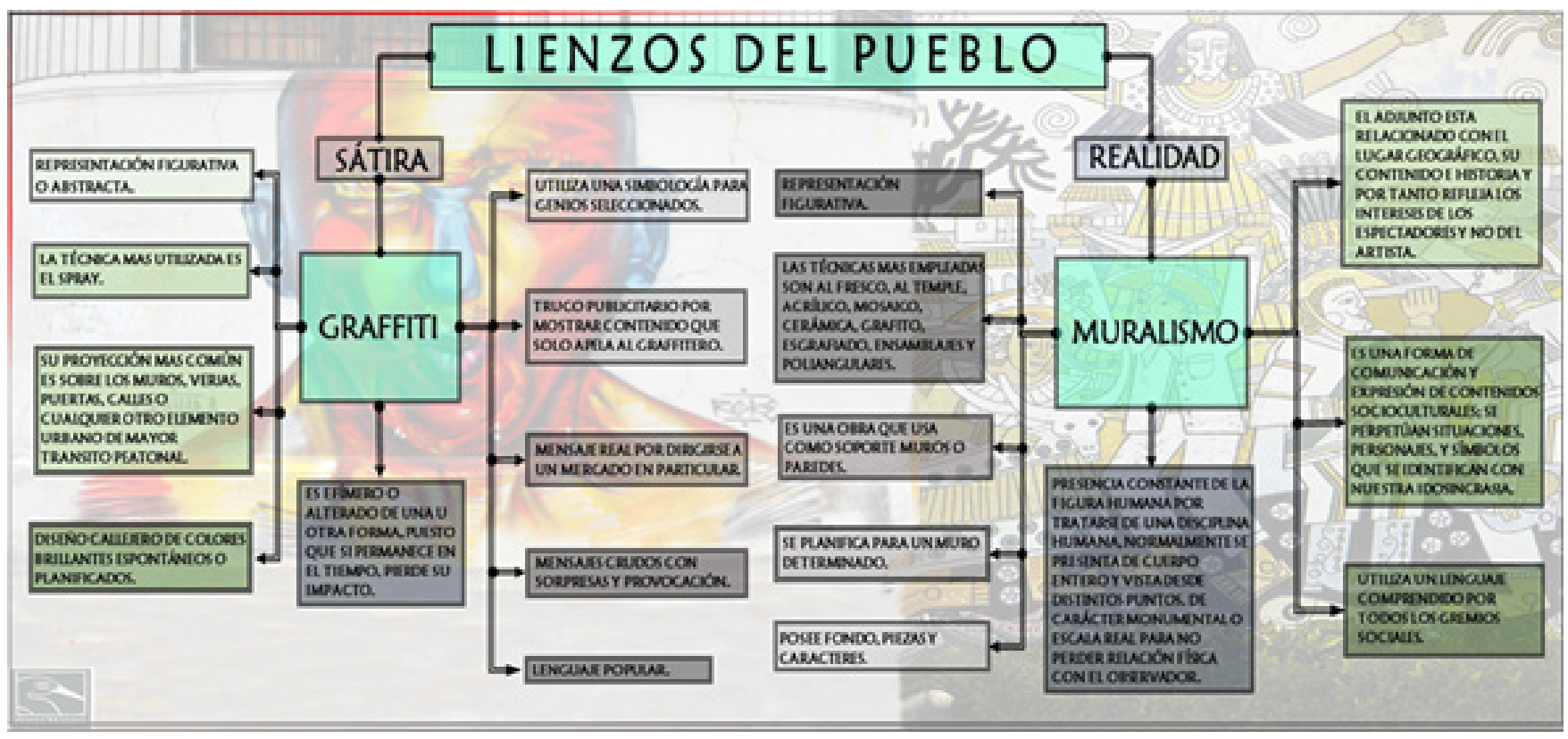

Figura No. 3 Diferencias entre el graffiti y el muralismo. Fuente, Elaboración propia 


\section{Resultados}

El departamento de Masaya es el más pequeño de Nicaragua (Ver Figura No.3), localizado a $20 \mathrm{~km}$ al sur de Managua con una superficie de 590 kilómetros cuadrados, sin embargo, por su densidad poblacional, de $226 \mathrm{hab} / \mathrm{km} 2$, lo convierte en el departamento más densamente poblado del país.

Es conocida como "Ciudad de las Flores" y cuna del folklore nicaragüense por su gran vigor cultural, que expresa con sus danzas folclóricas, gastronomía típica, festividades religiosas y carnavales paganos que reviven antiguas tradiciones indígenas.

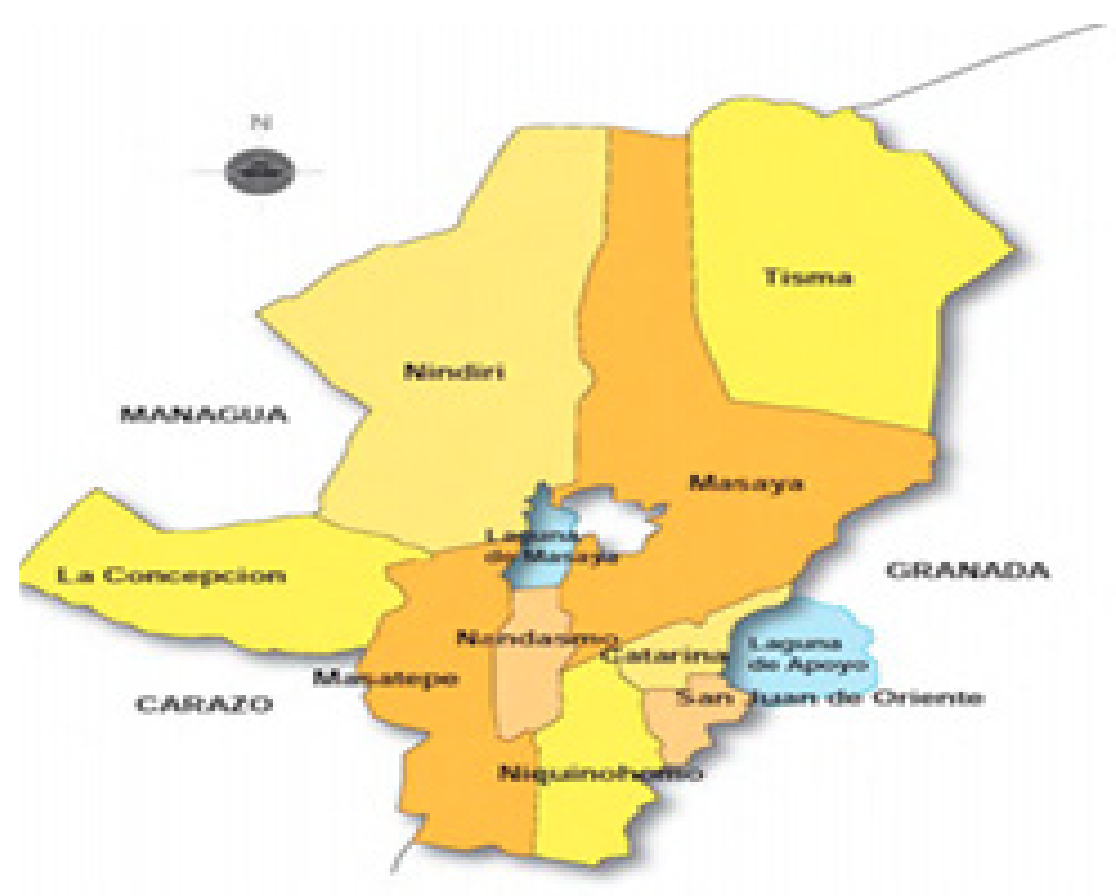

Figura No.4 Mapa del Departamento de Masaya

Fuente: Departamento de Historia. UNAN-Managua. (2009). Masaya, Historia y Vida.

Hoy en día en Masaya es muy practicado el arte primitivista (movimiento pictórico desarrollado a inicios de los años 80 por artistas plásticos de Solentiname) por los artistas jóvenes además, de otras tendencias que evocan a la naturaleza muerta y escenas de la cultura nicaragüense cotidiana. Pero, uno de los principales atractivos son las obras de arte plasmadas en las paredes de la ciudad, tanto murales como grafitis, cuyo colorido embellecen el casco urbano de Masaya y dan a conocer el talento de sus artistas.

A través de esta investigación se ubican los puntos de intervención más frecuentes del grafiti a través de la identificación de los elementos del paisaje urbano del centro de la ciudad de Masaya (Ver Tabla No.2), realizando una clasificación y su relación entre sí. 
Tabla No.2 Componentes del paisaje urbano en el centro urbano de la ciudad de Masaya

\begin{tabular}{|c|c|c|}
\hline $\begin{array}{l}\text { Estrategia } \\
\text { del paisaje } \\
\text { urbano }\end{array}$ & & Componentes básicos \\
\hline \multirow[t]{2}{*}{$\begin{array}{l}\text { Componentes } \\
\text { puntuales }\end{array}$} & $\begin{array}{l}\text { Edificios } \\
\text { relevantes } \\
\text { y carácter } \\
\text { patrimonial }\end{array}$ & $\begin{array}{l}\text { - Iglesia San Jerónimo } \\
\text { - Antigua estación del ferrocarril } \\
\text { - Casa Cural Parroquia La Asunción } \\
\text { - La Universidad Cristiana Autónoma de Nicaragua } \\
\text { (UCAN) } \\
\text { - Alcaldía de Masaya } \\
\text { - Casa Cural Iglesia San Jerónimo } \\
\text { - Iglesia San Juan } \\
\text { - Antiguo Cine Masaya } \\
\text { - Parroquia La Asunción } \\
\text { - Instituto Central } \\
\text { - Mercado de Artesanías } \\
\text { - BANPRO } \\
\text { - Iglesia el Calvario } \\
\text { - Iglesia San Miguel } \\
\text { - Estadio Municipal }\end{array}$ \\
\hline & & $\begin{array}{l}\text { - Antiguo Hospital San Antonio } \\
\text { - CECAPI } \\
\text { - Estadio Infantil "Guaracha Castellón” } \\
\text { - Colegio Salesiano } \\
\text { - Colegio San Sebastián } \\
\text { - Iglesia Magdalena }\end{array}$ \\
\hline \multirow[b]{2}{*}{$\begin{array}{l}\text { Componentes } \\
\text { longitudinales }\end{array}$} & \multirow[b]{2}{*}{ Calles } & $\begin{array}{l}\text { Avenidas } \\
\text { - Avenida San Jerónimo }\end{array}$ \\
\hline & & $\begin{array}{l}\text { Calles } \\
\text { - Calle Sur del Parque Las Madres } \\
\text { - Calle este del Parque Las Madres } \\
\text { - Calle Carlos Vega Bolaños }\end{array}$ \\
\hline \multirow{2}{*}{$\begin{array}{l}\text { Componentes } \\
\text { extendidos }\end{array}$} & \multirow{2}{*}{ Plazas } & $\begin{array}{l}\text { Plazas } \\
\text { - Plaza Kùhn } \\
\text { - Plaza de la Cultura } \\
\text { - Plaza Pedro Joaquín Chamorro (El Tiangue) }\end{array}$ \\
\hline & & $\begin{array}{ll}\text { Parques } \\
\text { - } & \text { Parque Central } \\
\text { - } & \text { Parque Las Madres } \\
\text { - } & \text { Parque del Malecón }\end{array}$ \\
\hline
\end{tabular}

Fuente, Elaboración propia, a partir del trabajo de campo. 


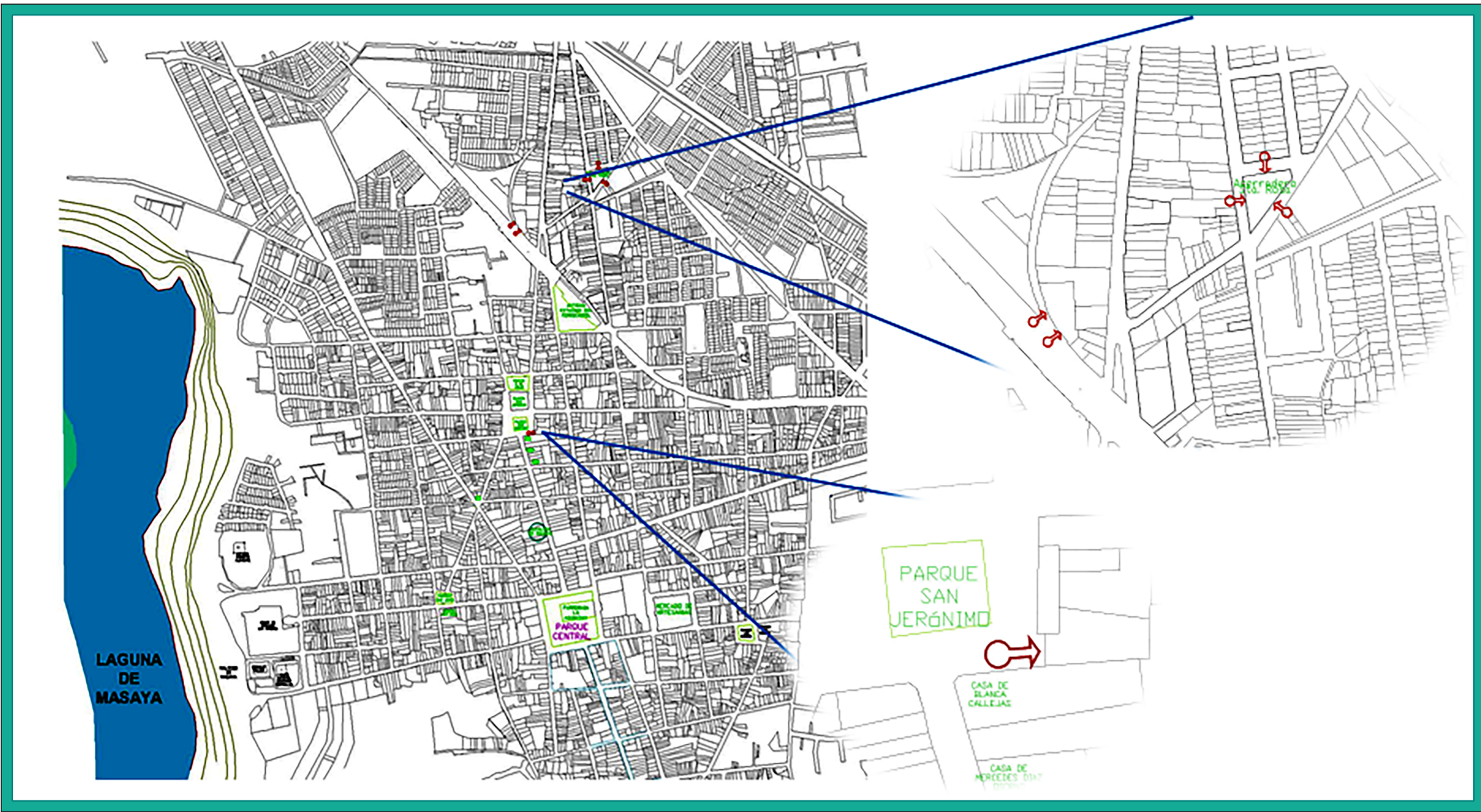

Figura No.5 Mapa de intervención del grafiti en el caso urbano de la ciudad de Masaya Fuente: Elaboración propia 
Para el levantamiento de campo se consideraron únicamente los grafitis expuestos durante los meses de junio del 2017. Se puede afirmar que los elementos urbanos más intervenidos por los grafiteros son las calles con la particularidad de formar intersecciones en $Y$ y de dirección quebrada (Ver Figura No.5), junto con las avenidas principales. En cambio, los edificios del circuito patrimonial junto con los parques y plazas del centro urbano, son respetados como parte de la imagen urbana que caracteriza a la ciudad de Masaya

Los grafitis en el centro urbano de Masaya se pueden clasificar desde su contexto urbano de la siguiente manera:

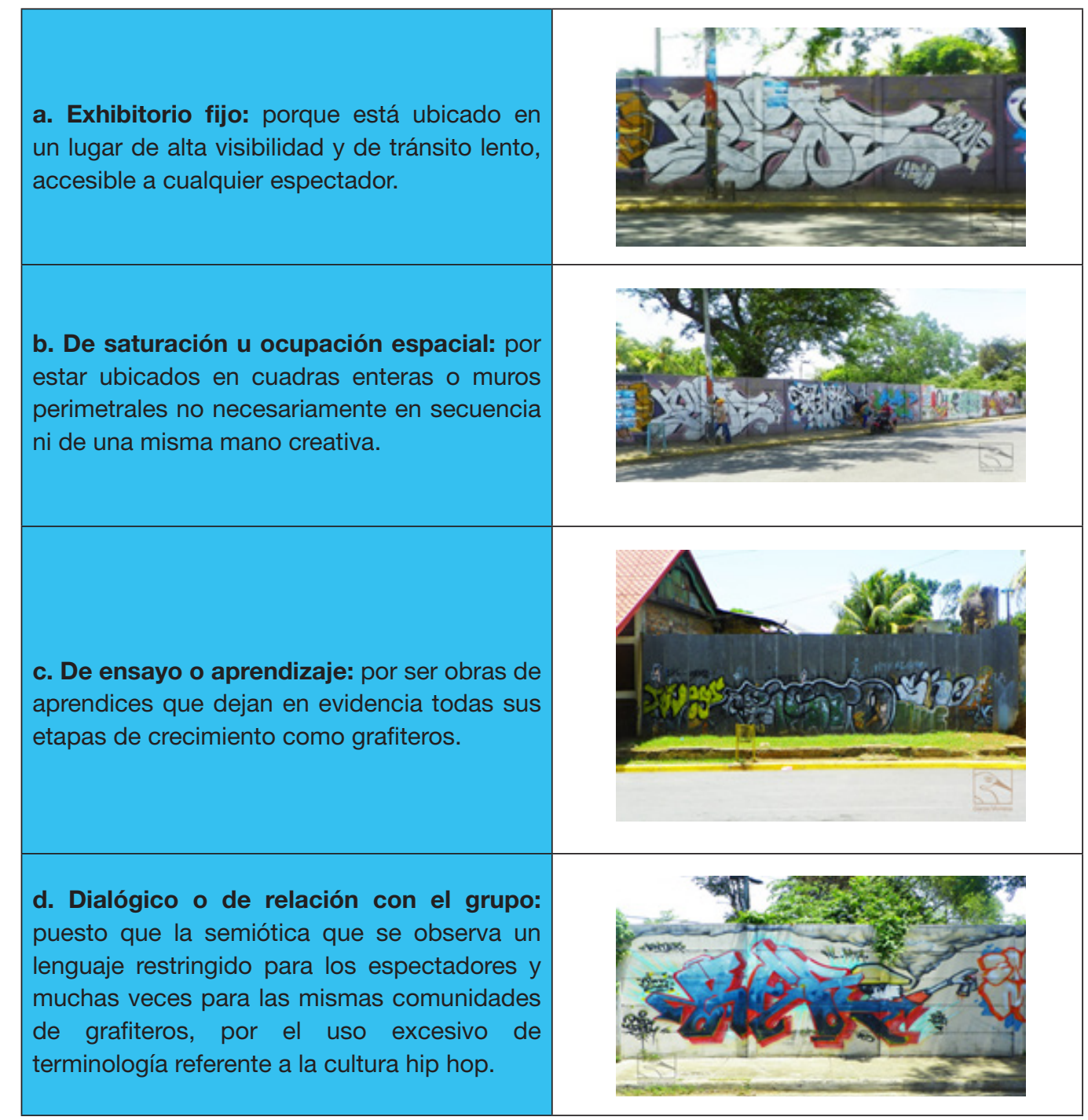

Tabla No. 3 Identificación de graffitis por su contexto urbano en la ciudad de Masaya Fuente: Elaboración propia

Otras variantes dentro de esta clasificación que no fueron identificadas en el centro urbano de Masaya son:

Exhibitorio con espectador móvil: porque no existen obras situadas en lugares de tránsito rodado rápido y en donde el lapso de tiempo para su observación suele reducirse a unos pocos segundos. 
Comercial o de encargo: puesto que no existen trabajos tanto de alta visibilidad pública como de contemplación restringida producto de una gestión de carácter privado o por encargo.

Exhibitoria en movimiento: no se han considerado dentro esta modalidad pudiéndose afirmar que se debe al carácter efímero que puede tener este tipo de superficies de trabajo (medios de transporte público urbano e interurbano), corriendo el riesgo de ser borradas en poco tiempo y comparadas con la producción publicitaria común.

También se pueden clasificar por su género de la siguiente manera:

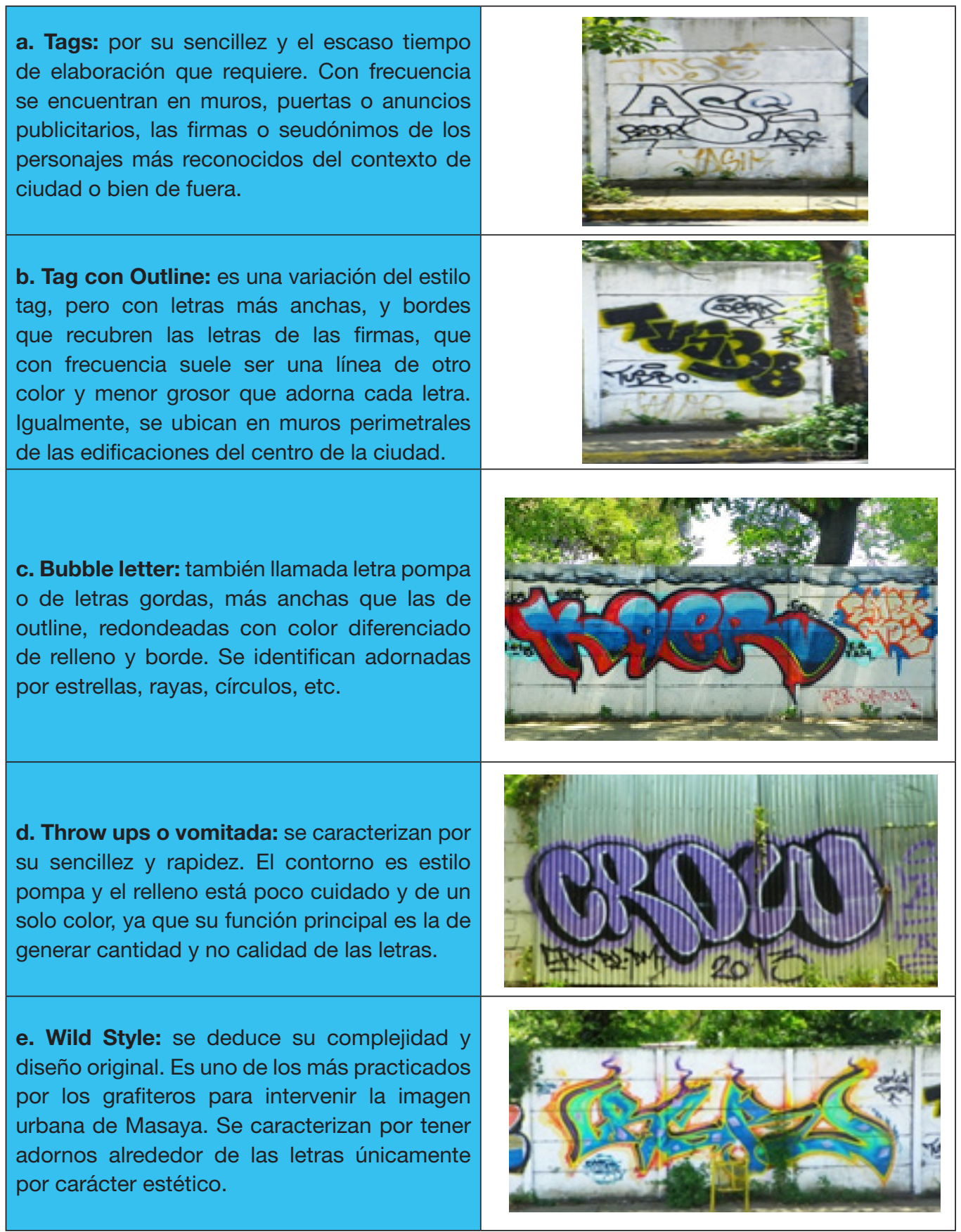




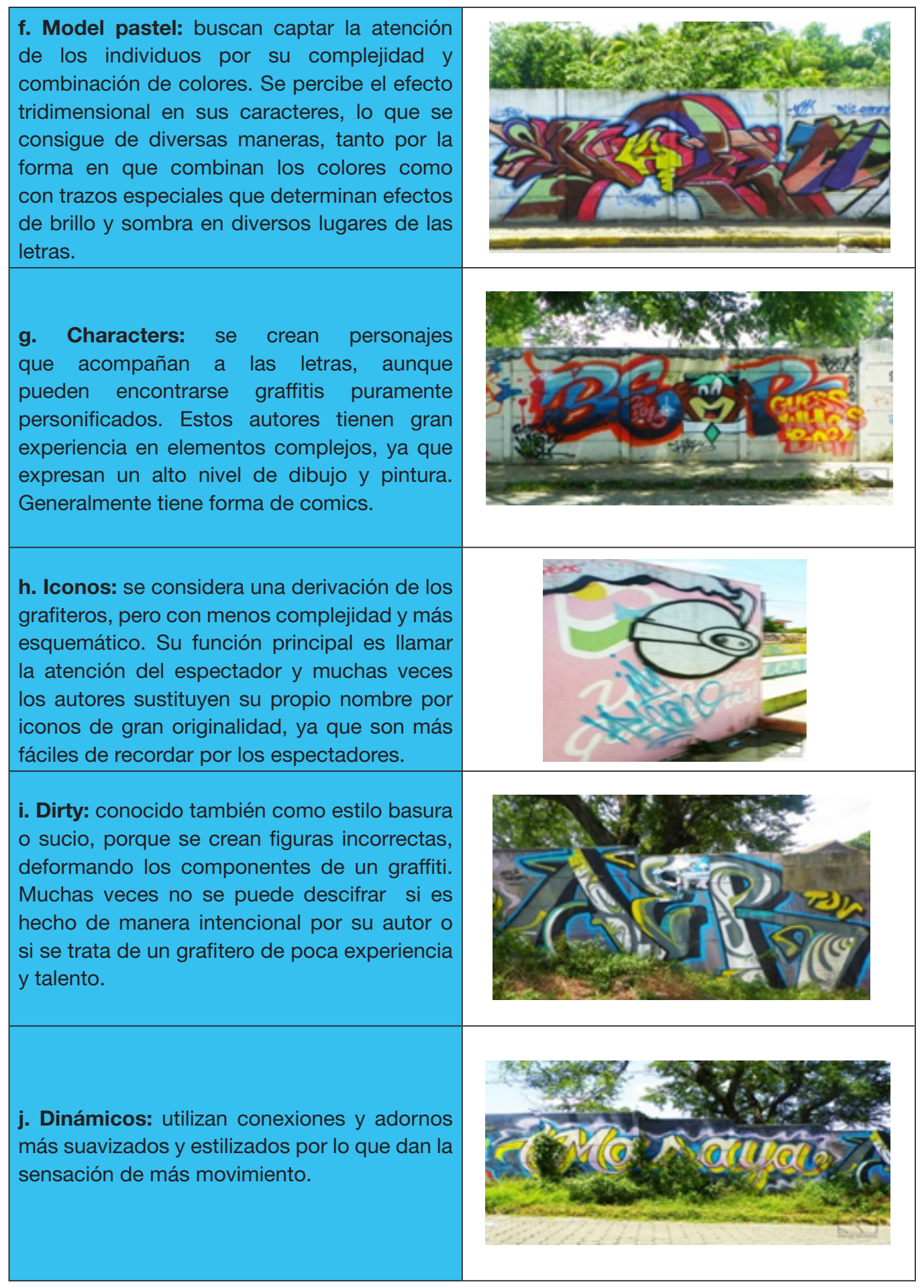

Tabla No. 4 Identificación de graffitis por su género en la ciudad de Masaya

Fuente: Elaboración propia 
Otras variantes dentro de esta clasificación que no fueron identificadas en el centro urbano de Masaya son:

j. Block letter: son altamente apreciados por su legibilidad y tamaño. Deben mantener un diseño sencillo, con caracteres gigantes cuya función principal es ser muy explícito, es decir, de una sola mirada los espectadores pueden determinar qué dicen, generalmente, a largas distancias.

k. Estáticos: se denominan así por su carácter geométrico, con ángulos, rectas y curvas pronunciadas.

Hay que recordar que el grafiti es efímero, pero su corto período de vida no limita el alto contenido ideológico, que va desde los principios y valores del autor, así como su crítica u oposición o la de su gremio ante ciertos fenómenos de la sociedad.

Pero, si de ideología hablamos, los grafitis identificados en Masaya no permiten descifrar la de sus autores en la mayoría de los casos, porque no resultan ser claros en su lenguaje, aunque por sus colores son visualmente atractivos y eso conlleva a que las imágenes atraigan atención de los transeúntes.

De lo que no cabe duda es de su contenido rebelde y revolucionario, lo que evidencia la riqueza de significados y matices, la que no siempre es apreciada por el observador ajeno puesto que desconoce los códigos gramaticales y semánticos de las formas realizadas.

\section{Conclusiones}

- Se puede afirmar que la imagen urbana de Masaya ha sido intervenida por el grafiti como una de las vertientes del arte urbano ocupando en su mayoría las calles y avenidas principales del centro de la ciudad.

- La investigación dentro de este caso de estudio evidencia que hay una fuerte actividad de parte de los artistas urbanos y un intercambio de técnicas dentro de la palestra pública.

- Los grafitis en Masaya a pesar de mantener su sentido de rebeldía y resultar poco descifrable para el espectador, se caracterizan por ser atractivos debido a sus formas y colores aportando a la estética de la imagen urbana de la ciudad.

- Se logró el objetivo de documentar el trabajo de los artistas grafiteros y de esta manera orientar a las autoridades municipales de Masaya, historiadores, filólogos, antropólogos y demás disciplinas relacionadas con la temática a proponer estrategias de intervención para el mejor manejo de esta disciplina artística.

\section{Recomendaciones}

- Solicitar al Instituto Nicaragüense de Cultura (INC), la alcaldía municipal de Masaya y el Instituto Nicaragüense de Turismo (INTUR), el apoyo para generar espacios y eventos junto con empresas que comercializan pinturas como Comex y Arti Sur en donde los grafiteros nicaragüenses puedan proyectar su trabajo artístico avalado por los promotores culturales.

- Divulgar todo tipo de investigación que aborde esta temática, a través de foros o conversatorios con especialistas en la materia y los mismos grafiteros para aportar criterios que mejoren las políticas de manejo y dinámica de esta disciplina artística.

- Que los resultados obtenidos de esta investigación sirvan de referencia para duplicar el ejercicio de levantamiento y análisis de grafitis en otros casos de estudio dentro de Nicaragua. 


\section{Referencias bibliográficas}

- Alcaldia de Masaya. (s.f.). Historia de Masaya. Obtenido de masaya.gob.ni: https://www. masaya.gob.ni/?page_id=124

- Bonilla, J. (2014). El graffiti y los derechos de autor. Obtenido de managuafuriosa.com: http:// www.managuafuriosa.com/el-graffiti-y-los-derechos-de-autor/

- Esquivel, A., \& Arce., C. (2015). Arte en Managua. Obtenido de ahoraenlaweb: https:// ahoraenlaweb.wordpress.com/2015/08/22/arte-en-managua/

- Kunzle, D. (2017). Los murales de la Nicaragua revolucionaria 1979-1992. (F. Kinloch, \& D. Traumann, Trads.) Managua, Nicaragua.: INHCA-UCA. Obtenido de http://ihnca.edu.ni/ publicacion.php/223

- Noguera, E. (2016). El grafiti supera la clandestinidad. El Nuevo Diario. Obtenido de https:// www.elnuevodiario.com.ni/nacionales/384283-grafiti-supera-clandestinidad/

- Vanegas, K. M., \& Márquez, J. C. (2015). Fotorreportajes "La rebeldia de la libertad" sobre el grafiti como forma de comunicación en las zonas urbanas de ciudad de Managua. Managua, Nicaragua: Universidad Centroamericana - UCA. Obtenido de http://repositorio.uca.edu. ni/3116/1/UCANI4048.pdf

- Departamento de Historia - UNAN Managua; Asociación de Municipios del Departamento de Masaya; Agencia Española de Cooperación Internacional para el Desarrollo (AECID). (2009). Masaya, Historia y Vida. Managua, Nicaragua. Obtenido de http://www.aecid.org.ni/wpcontent/uploads/2013/04/Masaya-Historia-y-Vida_01.pdf

- Pérez, M., Quinetero, G., \& Amoretty, E. (s.f.). Masaya, la "Ciudad de las Flores". Obtenido de insidemanagua.atavist.com: https://insidemanagua.atavist.com/masaya-la-ciudad-de-lasflores 


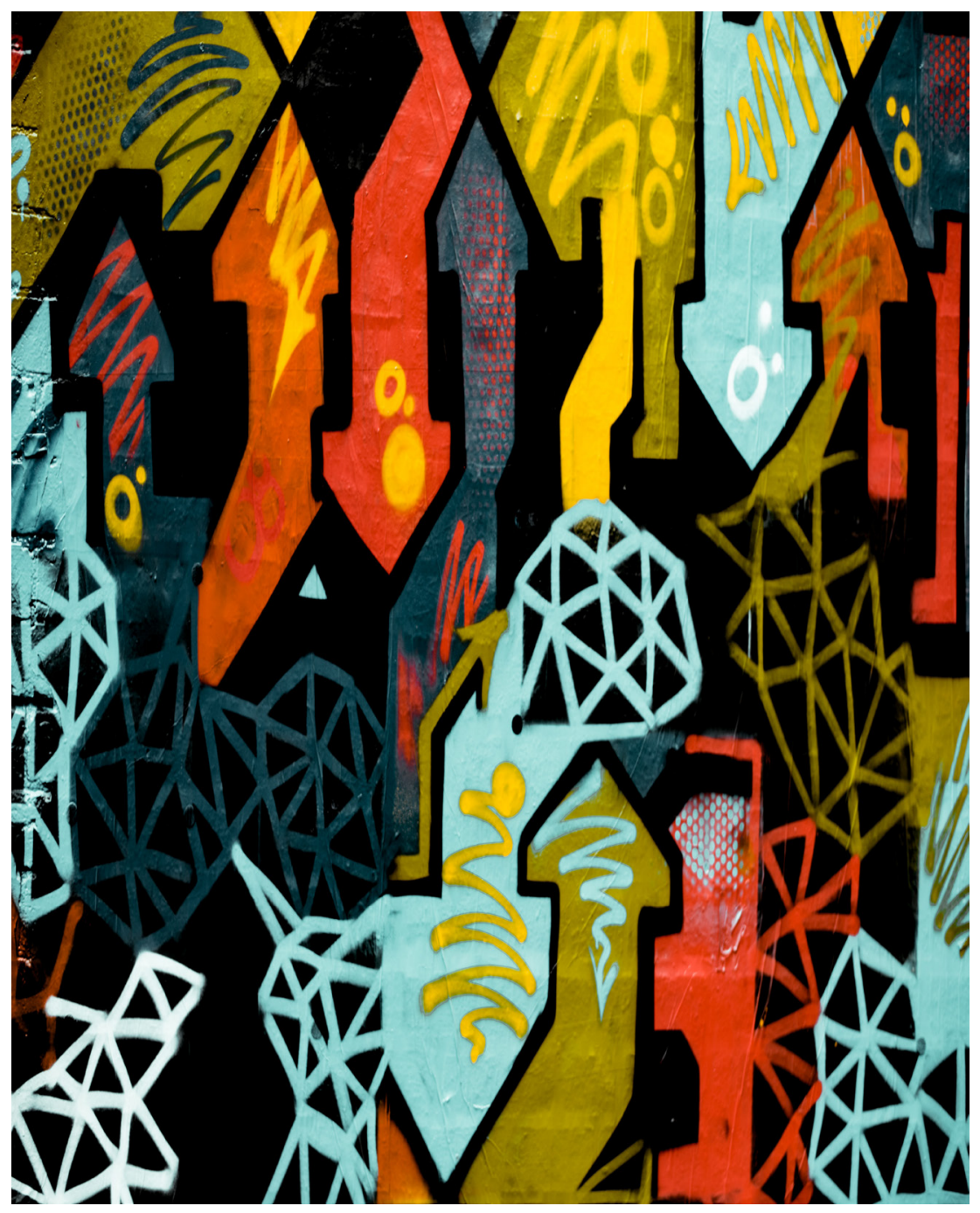

